PROOF COPY ONLY - ACCEPTED FOR PUBLICATION 12/09/2016.

\title{
Theatrical latency: walking Katrina Palmer's The Loss Adjusters
}

\begin{abstract}
In this article I introduce the term 'theatrical latency' as a pleasurable effect experienced when listening to sound in relation to visual perception. Latency refers to both the phenomena of audio delay (in feedback from analogue to digital conversion and the momentary lapses experienced when playing live with recorded music) and a theatrical sensation that comes from the reanimation of visual environments through aural framing. In this configuration, the notion of latency takes on a double meaning as both a recorded phenomenon and the retrieval of something dormant within physical objects, sites or materials. These ideas will be introduced through my experience of walking Katrina Palmer's site-specific audio work The Loss Adjusters (2015) on the island of Portland (UK). The audio tracks create an extended meditation on Portland, interweaving specific locations and histories with fictional characters and ghosts of the island.
\end{abstract}

Salomé Voegelin states that sound art 'gives us not the certainty of the visible object, neither actually nor metaphorically, but invites us into an invisible place that we co-inhabit for the duration of our listening' (2014, 88). In the following text I will attempt to reveal the 'invisible place' of my experience of listening on an audio walk The Loss Adjusters (2015) by Katrina Palmer, to ask questions about how listening to sounds can revitalise objects and sites in ways that produce new encounters and thinking. The walk, undertaken with headphones, is part of a trilogy of works made by Palmer called End Matter including a radio broadcast on BBC Radio 4 called The Quarryman's Daughter (2015) and a publication by Bookworks called End Matter made in collaboration with Artangel (2015). The text follows the path of the walk corresponding to three sites and accompanying audio tracks: 52 Easton Street, Bowers Quarry and St George's Church. The writing is constructed from my walking notebooks and personal photographs, describing encounters formed between the intimacy of the headphone sound design and the sites of Portland itself. It draws relationships between the kinds of listening and seeing made possible by the use of headphones and the interplay of sites, smells, people, animals, and objects that are met along the way. I have included a number of walking instructions that were supplied with a map accompanying the audio as a way of orientating the reader.

As the walk progresses, I consider how a form of theatrical latency appears to be at play, forming the central dramaturgy of the work through a complex interplay between the acoustics and visuals of Portland (the wider landscapes of quarries, a churchyard, cars, people and animals) and the recorded manipulated sound of the headphones (the textures, voices and narrative fiction of the sound mix). In the first part of the walk, 52 Easton Street, I begin by considering how Palmer outlines a philosophy of presence in the text of her work through her own speculations on the materiality of things and how they might evoke histories, memories and emotions by shifting the relationship between reality and fiction. In the second part, Bowers Quarry, I draw upon Salomé Voegelin’s concept of ‘sonic materialism’ $(2014,85)$ as a means to think through the interaction of the sound and visuals (site and landscape) in terms of a materialist interplay and how this activates the liveness of the walk. In the third part, $S t$ George's Church, I consider how Hans Ulrich Gumbrecht's (2013) notion of latency as a phenomenological effect to suggest an experience of presence rather than repression and the notion of Stimmung in relation to a prevailing mood and voice that has an aural dimension. In this configuration, in relation to sound art, latency is not just a reference to a delayed feedback when tracking audio but becomes an active experience through the retrieval of 
something that lies dormant. I conclude by considering how The Loss Adjusters enables an interplay between sound, site, fiction and reality to arguably produce one of the pleasurable satisfactions of engaging with good sounding practice, the satisfaction that the listener is being given agency within the making of the work, becoming part of the storytelling apparatus. This participation is innately pleasurable because it promotes an active and engaged listening experience that physicality locates the listener within the site of the work and producing the embodied sensation of feeling present.

\section{Easton Street}

The walk begins at number 52 Easton Street in the offices of the Loss Adjusters, an agency of spectral figures who attempt to record and recalibrate the losses of Portland. Portland is an Island just off of the Dorset coast connected by a raised road reaching out into the sea. The island is known for its limestone quarries and archaeological importance as part of Dorset's Jurassic Coastline. Exactly what losses the adjusters are investigating is undefined, but they are inextricably linked to the fabric of the island. The audio starts with the sound of photocopiers and a voice, one of the adjusters, who acts as a narrator: 'The Loss Adjusters are at all times woeful: an inherent disposition confirmed by their close proximity to Portland Stone' (Palmer 2015, 5). It is revealed that the Loss Adjusters are bureaucrats working from the offices to complete 'catalogued investigations into materiality' (7). The adjusters appear spectral as they talk of shifting - or at least seeing - through time, from the prehistoric origins of the rock through to the present day lives of the people of Portland.

I hear the audio whilst wandering around the offices. All that is left are bare fittings: faded brown and olive green carpets, broken faux wooden paneled walls, tired office furniture, desks with plastic veneers and metal filing cabinets. It is populated with photocopiers and fax machines that are unplugged and pushed against the walls. It is a silent space, a space that has been abandoned some time ago.

The audio is full of voices. Each voice is identified by a different timbre processed through audio effects. The Loss Adjuster's voices sound as if they are mediated through photocopiers, compressed, leveled out, and tipped with an analogue edge. The sound construction is based around a thick layering of voices, male and female, echoing and repeating certain words and phrases. There is a clear reference in the sound design to the action of the photocopier, replicating an original document or image as a ghostly double. The appropriation of a visual machine - such as the photocopier - into a represented sound, reinforces the relationship that is being established between the sound design and the visual textures and objects of the space it is occupying. The central voice comments on the activity of the space, claiming that the adjusters 'find the low hum, indicative of the reproductive capacity of the printers and copiers, reassuring.' (Palmer 2015, 7). The 'reverb' profile is clearly mapped onto the acoustics of the room and the familiar claustrophobia that is associated with small office spaces with few windows and strip lights. Listening to this, the space is transformed and animated, gradually recalibrating the way I am being asked to look. The sound brings a heightened perception to the texture of surfaces and the smells of the carpet. I start to think about spaces that I have worked in and the particular sense of melancholy that comes with the decor of businesses that have been abandoned or unloved. The central voice, a male narrator, has the heightened elocution of a classically trained actor and this establishes the tone of a storyteller, a poetic rhythm that continues throughout the audio. In contrast to this, a new voice is introduced, a writer-in-residence, which appears to be Palmer herself (although this is not made explicit). She has taken up residency in a space above the Loss Adjuster's office. Her voice is identified by a cleaner natural sound taken from a field recorder or dictaphone, unprocessed by the photocopier effect. The writer-in-residence 
acts like a conduit between the present day and the time-travelling status of the Adjusters. She describes her uncovering of the Adjusters' files and how she is attempting to unravel stories of the Island from their perspective. Casting herself as a fictitious writer is pertinent to the interplay of the space of Portland and the fabrications and stories that might be told about it.

The text establishes this interplay of fiction and reality through the outlining of a philosophy of presence that the Loss Adjusters represent. As Palmer states, the Loss Adjuster's files 'investigate a tendency for the contemporary mind to engage with things that have only the most fleeting independent existence, or else things that are self-declared fabrications' $(2015,11)$. In the same way that the sound is recalibrating the way in which the listener is being asked to look at objects and spaces, the text, and the philosophical proposition it contains, is offering a way of thinking about the very nature of encountering the materiality of these objects and spaces, asking the listener, like the Adjusters, to make 'strategic decisions about their perceptions of what is real and what might be fiction' (11). In 52 Easton Street this means of encounter is set-up as an invitation. What follows on the next part of the walk is an uncovering of the Loss Adjuster's files on the island, to walk with Palmer as the writer-in-residence to discover 'how the reality of stone's loss can be made manifest' (9).

Turn right out of 52 Easton Street, walk up the pavement for about 100 metres, then cross the road just before the bus stop. ${ }^{1}$

As I exit the offices I notice two men talking in front of an open garage door. I see that the garage contains rolls of green carpet. I am still wearing my headphones with the second track paused. I take a moment to write about the vulnerability and enclosure that comes with wearing headphones. Listening to sound and music on headphones directly changes the experience of perceiving. It the case of The Loss Adjusters the sound track is constructed not just through voices, but through the sound of objects (photocopiers, paper, shoes, carpet, etc.). As Salomé Voegelin states, 'listening's focus on the dynamic nature of things renders the perceptual object unstable, fluid and ephemeral: unsettling what is through a world of sonic phenomena and audible spirits. Sounds are like ghosts' $(2010,12)$. This spectral instability, as a form of aesthetic effect, has a tangible impact on the way that materials and objects are perceived. The cumulative effect of this first encounter with the sound design is reconfiguring the way in which I am being asked to look and see the visual environments I am moving through. I realize that the invitation, through the audio, is to alter my everyday perceptions of how I look at things. It is the first part of the conceit that I choose to be a part of.

Walk straight ahead into Victoria Place, a small road with tarmac. Continue straight ahead as the tarmac road changes into a rough narrow path, keeping the metal fence to your right. When the path forks, take the left hand path, keeping a wooden fence to the left. At the next fork, keep left and you will go up a small number of steps. At the next fork, take the right hand path. There is a small field and a row of houses to your left, and a quarry to your right.

After about 50 metres you come to a small cricket ground. Walk around the fence to the right of the ground. Continue on Public Footpath for about 100 metres until you see a metal cylindrical tank to your left. Cross the track before the tank, and take a small rough path up the slope. Continue for about 100 metres, keeping the cemetery wall and St George's Church to your left. You come across some large flat slabs of stone with Bowers Quarry in front of you.

\section{Bowers Quarry}


I am standing overlooking Bowers Quarry and press play on the second track. A chorus of softly wailing voices provides a backing to the speech of the writer-in-residence. She is standing in the same position that I am. Her voice is divided between a narrated text, describing a scene she witnessed in the Quarry, and repeated fragments of speech reaffirming her location: 'I'm on the edge' (Palmer 2015, 18). The Loss Adjusters then tell a story about a gravedigger who works in the churchyard and who is seen with an unidentified and gutted corpse in his wheelbarrow, first in the quarry and then by a freshly dug grave. The text describes the detail of the burial with splintering rock, steel and mounds of soft mud. There is a point in the narrative where the Loss Adjusters intervene within the story as a kind of spectral council, meeting the gravedigger while appearing from behind a rock and questioning him about the solitary burial. They both record what they are witnessing and interact with the characters, acting out of time with the narrative event. I am told at one point in his life, the gravedigger has fallen over the edge and that he has since been brought back to the surface, as if what I am hearing is a man burying himself in a continual cycle, like Sisyphus, repeatedly shifting rocks.

A space opens up between what I am looking at and what I am hearing. I am not just imagining the scene of the body hunched in the wheel-barrow and the actions of digging but instead I find myself intently watching the progress of a large work truck and numerous men in hard hats at the base of the quarry as they move large slabs and cubes of rock into different sections. I start to identify categorizing systems as the rocks are marked with red and blue spray paint and numbered based on their shape, size and weight. I notice the system of roads that link the various parts of the quarry together. The audio draws my attention to the lines of houses on the estate to the far left of the quarry and I try to locate the prison referred to in the text. I am not sure if this place is still there, or if it has been removed, or if it is a fictitious place that exists purely in the narrative. All the time I am looking into the quarry I am aware of St George's Church behind me. A man walking two dachshunds is calling to me over the graveyard wall. I break the audio and remove my headphones: 'is there as quarry there?' he asks, 'can you see in?'. The slab of rock overlooking the quarry has been selected because it offers a panoramic view point to give the listener the wide spread of the landscape to experience, like a revolving series of views or perspectives for the audio to animate. It occurs to me that this animation is not intended to simply represent scenes or characters but operates through the philosophy of presence evoked in 52 Easton Street, akin to what Salomé Voegelin calls a 'sonic vitalising of the visual world' $(2014,98)$.

According to Voegelin, such a vitalising happens not just in the object or subjects that are being perceived, such as the stones in the quarry or the story of the gravedigger but through the relationships established between them, a 'reciprocity through which we build the sense of the material world not as separate from us nor as made from abstract entities, but through our inhabiting of the commingling of things as events'. Because sound-based works are made live through their duration they create live events to be experienced rather than simply received. This liveness is activated through the chance encounters of such a space, not orchestrated by Palmer as the artist but set-up as a possibility. Furthermore, Voegelin develops this notion of an aural vitalising of the visual world as a form of 'sonic materialism' which functions as 'a permanently present action of connecting, disconnecting, and reconnecting'. Audio tracks in sound art are constantly reconfiguring the dynamic of the encounter with the work, 'action as interaction, creating not itself but the event of the moment, the aesthetic moment of the work and of the everyday as the commingling of what there is together rather than through deduction and adding up what there is apart' $(2015,98)$. There is a private pleasure in having such an experience in this place on a particular day and at a particular time. I am the only person having this experience, I have control of it but at the same time I am accepting the 
conceit of the work; it is a two-way street of interaction, connecting and reconnecting aspects of the sound and space together.

Keeping the cemetery to your left, continue along a narrow path, with a metal fence and Bowers Quarry to your right. At the end of the path, go up a small incline, and down the other side. You will see an all-weather sports pitch in front of you. Turn left here, and walk beside the cemetery wall.

I come across the fenced sports pitch at the edge of the quarry between some scrub land and the housing estate where some teenagers are playing football. The sound of the ball echoes around the playing fields as it strikes the metal fence. I start to think about the relationship between reverb design of the soundtrack, held within the enclosures of the headphones and the range of spaces that the walk involves. The reverb profile of the soundtrack is set up to contain the voices, to make them sound as if they are present within a self contained non-space neither 'on site' in the landscape in which the work is played out or in any other fictitious location, as Augoyard and Torgue claim, reverberation is inscribed with being 'socially perceived as an indication of solemnity and monumentality' $(2011,116)$. The sounds of the Loss Adjusters in the headphones suggest such a solemnity, occupying a space of isolation, looking onto the actions described in the narrative but not physically within the space of the actions themselves. This is contrasted by the scale of the quarry and surrounding fields, estate and churchyard, which intervenes with its own soundtrack; the crashing of rock on rock from the lorries; the birds, dogs and people that populate the area; and the sounds of a football crashing onto metal grills.

Before you arrive back at the main road, turn left and walk back towards the church, remaining on the outside of the new cemetery to your left. Continue through the wooden gates into the old graveyard of the church.

\section{St George’s Church}

In this part of walk there is a choice for how to listen to the audio. It can be done while walking around the churchyard or inside St George's Church. Looking across from the graveyard the top of Bowers Quarry can be seen. The view sets out another layering of the stone, from the graves to the boundary wall and then to the raw rock of the quarry beyond. The cycle of death is closely tied to the physical digging up and repurposing of the stone that is laid out to see. This section of audio opens with a field recording, at least I think it is, of a worker hitting a rock with a pickaxe and singing a rhythmical work song in time with the beating. A refrain of piano music plays. The use of music introduces a cinematic aspect to the work to produce a form of sonic ‘vista'. This section tells the story of two Quarryman's Daughters, figures in the community who once met the Loss Adjusters in the quarry. One of the daughters tells a story about being explicitly riveted into a freeze, captured by the Loss Adjusters, and a scene in which she witnessed her home being crushed by a giant stone. The combination of actors speaking written text and the sound of authentic work songs continues the slippery relationship that Palmer is building between the interplay of fiction and reality. To problematise this relationship even further, the voices that I am hearing are not 'live' but recorded - 'sent back' through the technology of recording and headphones so they return as a kind of haunting. As Mark Fisher states, 'in terms of sound, hauntology is a question of hearing what is not here, the recorded voice, the voice no longer the guarantor of presence' $(2014,120)$. It strikes me in that moment that Palmer's audio tracks are opening up a space for thinking as much as an expectancy to follow the story. As in part one, the audio in part three has a density that allows my mind to wander because it does not focus on a single line of 
listening but folds and revels layers of soundtrack so that I have to decide on my own focus as I walk amongst the stones. I miss sections: I don't quite follow the trail of narrative; different parts of the text and sound connect at different times. I am not sure what is present and what is not.

This experience compares to what David Goodman calls a form 'distracted listening': a state of attention occurring from how accustomed listeners are from the constant bombardment of multiple sounds within everyday life. The ubiquity of mobile gadgets, background music, radios, and increasingly busy street noise has, according to Goodman, resulted in a range of sophisticated forms of listening to adapt to the complexity of such an aural environment. Goodman claims that a taxonomy of new forms of listening can be distinguished, from 'passive hearing to active listening', which enables listeners to disentangle “"informational” from "dimensional” and "concentrated" modes' $(2010,16)$ of hearing, building individualized repertoires of how aural culture is consumed. Listening to music or sound on portable devices is characterized by a fading in and out between concentration on the particular sounds and information that is being heard and becoming a 'bed' or background to an experience. The construction of the soundtrack of The Loss Adjusters appears to be conscious of the listener's aptitude for multiple modes of listening, allowing the space for distraction to become a part of the experience so that the locations in which the sound is heard can be experienced in visual and aural dialogue with the sound track itself.

I think about rewinding and listening again but I get the sense that this is not necessarily important; I am out-of-step with the track now at about 30 minutes of listening. As a listener I am faced with a choice. I could listen again to make sure I am not missing anything or, like watching a live performance, I can accept that my experience of the work does not need to be so stringently analytical. I realize that my unease is because I have started listening to it as if it is a dramatic text, offering a narrative that is to be imposed upon the island. This experience correlates with Gertrude Stein's claim that theatrical plays always made her nervous because of the sensation of being 'out of time' with the action. As Hans-Thies Lehmann states, Stein's unease was born from the fact that dramatic plays always 'referred to a different time (future or past) and demanded a constant effort on the side of the viewer contemplating it'. The Loss Adjuster's is, in fact, more akin to Stein's own concept of the 'landscape play', a theatrical form that focuses on the 'defocalization and equal status for all parts, a renunciation of teleological time and the dominance of an 'atmosphere' above dramatic and narrative forms of progression' (Lehmann 2006, 63). As I continue to walk amongst the gravestones I am aware that this experience of landscape it defined by a sensation of a latency of time that is innately theatrical, which appears to be operating as the various aspects of production (sounds, text, site and objects) that are constantly reforming and relinking with each other, not as a sequence of clear understandable events, but as a set of messy thoughts and feelings that land and link up at various points of the experience.

\section{Theatrical Latency}

Hans Ulrich Gumbrecht in his book After 1945: Latency as Origin of the Present (2013) develops a notion of latency as a form of presence - not repression - of past events. For Gumbrecht, latency is a phenomenological series of encounters which draw upon collective memories and material conditions to understand contemporaneous actions and emotions. Latency, in Gumbrecht's configuration, is not the coming back of traumas or joys, which have been buried and repressed psychologically but accounts for the experience of things transformed and manifested that have once existed. This idea has as much of a relationship to storytelling and fabrication as it does to the recollection of empirical fact. Gumbrecht's idea 
of latency as a phenomenon holds to the experience of the present moment and not just the representation of things that have passed. Gumbrecht likens an encounter with latency to the presence of a 'stowaway':

In a situation of latency, when a stowaway is present, we sense that something (or somebody) is there that we cannot grasp or touch and that this 'something' (or somebody) has a material articulation, which means that it (or he, or she) occupies space. We are unable to say where, exactly, our certainty of the presence comes from, nor do we know where, precisely, what is latent is located now. And because we do not know the identity of the latent object or person, we have no guarantee that we would recognize this being if it ever showed itself $(2013,23)$

The notion of a 'material articulation' of something that is hidden suggests the possibility of an encounter with an object's materialism (be it sonic or visual) to retrieve something that is latent, to glimpse the presence of a stowaway hidden beneath the surface. Furthermore, the appearance of what is latent might have been transformed during its state of seclusion, as Gumbrecht continues, 'what is latent may undergo changes while it remains hidden. Stowaways can age, for example'. The state of latency, or how it appears is therefore difficult to locate as it does not return as a definable object or subject to be considered but is instead experienced as a sensation - a thinking - evoked from the encountering of objects and subjects. Gumbrecht writes of the difficulty in the retrieval of things that are latent as there are no methods to directly identify things that lurk below. He asks the question: 'how can we be so certain that something latent is 'really there' if it eludes our very perception?' (2013, 23). This retrieval can be attempted through the making of an artwork. The apparatus of art making (in this case sound tracks encountered in a landscape) holds within it the possibility of recalling, or at least eliciting the presence of latency because it is a form that investigates material encounters: opening an access point to 'material articulations'.

The potential of sound art to produce this kind of material articulation could be described as what Gumbrecht, in relation to latency, identifies as 'Stimmung' (24). Stimmung is a German word, which has a double meaning. Firstly, it translates as a mood, a metaphorical term to refer to a sense of a prevailing atmosphere. Secondly, it has its etymological root in the German word Stimme - voice. Gumbrecht claims that this form of voice suggests the 'presence of a material touch, typically a very light one, on the body of the (ap)perceiving party'. As an example, he claims that this is like the invisible yet material impact that weather, sounds and music have upon us. Importantly from the perspective of latency, Stimmungen eludes to the notion that there is something lurking behind the thing perceived that 'emerge as effects of latent conditions but they do not necessarily originate with them'. Gumbrecht utilizes this concept as a tool through which to speculate on the acts, encounters and moods of post-war Europe: 'Stimmungen form an objective part of historical situations and periods. As such that is, as conditions of 'objective sensibility' they constitute a central, if largely neglected, dimension of what can make the past present - immediately and intuitively - present to us.' (24). What appeals about this concept - as a tool for speculating about the effects of sound art - is the innately material and aural dimension it occupies. Stimmung refers to the simultaneous experience of a material voice and the tuning of a mood, a sensation that evokes something returning through the encounter with sound.

Voegelin's claim to the 'sonic possible worlds' $(2014,9)$ evoked through sound art alludes to this potential: 'listening to the concrete materiality of sound we do not order things as objects and subjects, neither according to a higher power, nor in a humanist scheme, but eschew ontology, history, and discipline to participate in the possibilities of what there is' 
(88). This participation in the possibility of what there is - a mood or atmosphere - could be what I had experienced in the rooms of 52 Easton Street, the edges of Bowers Quarry and the churchyard of St George's Church as a cumulative effect of the work as a whole; the presence of stories and centuries of human activity on the island; the rubbing together of the degradation of the churchyard; the modern estate; the sounds of the sports cage; the new possibilities of freshly broken rocks. The presence of latency in The Loss Adjusters is gradual, appearing in waves rather than easily definable moments, like the milieu of a landscape play, a broader sensation about the phenomenological encounter of experiencing place through the triangulation of sound, object and listener.

It is this configuration of an encounter with place that I refer to as the idea of a theatricalised latency. In The Loss Adjusters the sound apparatus of audio tracks and headphones replicates the action of a theatre machine, operating between mimetic representations (the fictional characters and stories of the soundtrack) and reframing the live presence of objects (landscapes, people, animals of Portland). Within the mimetic machinery of the theatre, sounds and objects shift between an assured 'thingness' (...it is that) constructed by their representational function, and an objective presence that originates from bare materiality (...what is that?). This phenomenon is a form of theatricality that can also be located in work beyond conventional theatre making structures within hybrid forms of art making such as live art, installation, and most significantly here, sound art practices. Such practices have employed the theatrical as a concept of aesthetic relationality, brought to the fore by Michael Fried's critique of theatricality in minimalist sculpture in Art and Objecthood (1967) as a condition of art objects to exist only through the presence of the spectator. As Manuel J.Borja-Villel states, Fried exposed that the encounter with art object 'was no longer explained in relation to an external object which it represented, nor did it refer to itself instead, it conformed phenomenologically to being experienced by the viewer' $(2007,21)$. The experience of theatricality, in a non-theatre context, derives from locating the spectator in relation to the work through their participation in its construction, mediated through the intentionality of the artist.

As Borja-Villel continues, these hybrid forms can be traced from Artaud's Theatre of Crulety (2007, 94); the Dadaist and Surrealist experiments in performance (78); Grotowski's Poor Theatre (102); and Tadeusz Kantor's theatre happenings (123), to reconfigure conventional structures of dramatic, theatrical and spatial dramaturgy so that 'the scenic space ceases to be a "substantial" location and creates its own boundaries through the play of relations of representation' (21). It was an attempt by practitioners to shift away from a theatre of representation, to what Alain Badiou calls 'a theatre of operation' $(2007,23)$ : $a$ theatre without theatre because it maintains what might be conceived to be theatre's essential characteristics 'of thinking in relation if not to a text to be interpreted at least to instructions or statements to be performed, that is, complemented or used as rules which can then be revised' (Elie During in Badiou 2007, 23). A theatre of operation deliberately draws attention to its own making - its phenomenological reality - rather than the things it might be said to directly represent.

There is a direct correlation between these forms of 'theatres of operation' and what Helen F. Wilson calls the 'more-than-representational methods' of soundwalks. Wilson maps the range of sound walking practices that have emerged from the collaborations between geographers and artists 'where the embodied and experiential accounts of space and landscape have been prioritized' in an attempt to encourage forms of 'active listening through a combination of narration and sonic representation' $(2016,163)$. Wilson cites how sound walks that utilize a recorded score (a set of operative rules) such as directions and references to objects and topographies of landscape, to open the possibility of an improvised relationship between listening to - and viewing - a landscape and the guided nature of the walk itself, 
which can 'debunk divisions between material and immaterial' contexts in favor of drawing on the 'qualities of liveness' (166). This utilization of 'liveness' as a walking practice to uncover and investigate place and landscape is cited by Wilson in the audio walks of Janet Cardiff through the streets of Whitechapel and Spitafields (167), Micahel Gallager's binaural recording audio-drifts in Kilmahew Glen, Scotland (166), and Hayden Lorimer and John Wylie's 'listening walks' as a method of mapping and interpreting landscape (165), 'working to unravel fixed representations and to draw attention to sonic registers that are often ignored' (167). All of these strategies utilize the soundwalk as a method of experiencing and participating in what there is rather than what might be represented: the Stimmung or atmosphere of place defined through the listener.

In The Walkman Effect (2012), Shuhei Hosokawa develops the embodied experience of soundwalks further to listening to audio on headphones. Hosokawa claims that 'walkmans' are innately theatrical because they 'organise an open and mobile theatre by means of its clandestine manoeuvres'. The intimacy of listening to a soundtrack or narration sonically frames the everyday that implicates all passers-by into the 'walkman theatre, as either actors (holders) or spectators (beholders)', like the moment I viewed the men by the garage door outside 52 Easton Street. Hosokawa argues of the potential of the 'walkman' to transform such spatial experience of urban environments to construct and deconstruct the 'network of urban-meaning' as it instills an agency in the listener to make and interpret urban space: 'it is up to you to choose your 'role' in this 'society of spectacle': actor or spectator' $(2012,115)$. Furthermore, Hosokawa's reading of the 'Walkman effect' suggests that the portability of sound not only acts as a theatrical device but extends the effect to the possible instigation of transformation of place, to have the potential to actively shape and reconfigure the spaces in which the soundwalk is happening, interpretation of sound in context as the prelude to future actions.

The Loss Adjusters utilizes the 'more-than representational' forms of the soundwalk, and the theatricality of the 'Walkman Effect' to construct an operational dramaturgy where the work is created through the embodied engagement between the materiality of Portland and the immaterial 'improvisation' of the listener. This process is theatrical but not theatre because the moments of theatricality come from the experience of encountering latency: sensations of place that are nascent, both in the stories and sounds of the island and the physical presence of the objects found there (gravestones, rocks, and buildings). This sensation of latency does not appear at any singular moment but through the duration of the walk and within the moments of reflection I have throughout the days, weeks and months following. Listening and seeing in this configuration is not as 'a receptive mode but a method of exploration, a mode of 'walking' through the soundscape/the sound work' (Voegelin 2010, 4). Palmer is able to initiate this through the utilization of the conventions of the theatre machine as a structuring device that constantly forms and reforms the listeners' relationship with representation through the exposure of the soundwalks operational conceit, between the spectral characters of the Loss Adjusters and the field recordings of songs and actions from the island, developing interplay between what is real and what is fiction.

\section{Conclusion: Sounding Good}

As I stand alone with my headphones in St George's Church a man comes in and asks if I would like to know more about the church's history. He tells me that it is unique because all the pews face away from the altar and into the central concourse. He tells me a story about how all the pews are individually owned by various families on the Island. He shows me records of how they have been passed down between generations and how, although he is not a native Portlander, he has found a connection back to his own family roots who own a pew in 
the church. Back outside I finish the audio tracks by hearing the sound of the workers keeping rhythm by singing and hammering, metal clashing on the surface of rock.

Leave the graveyard through the wooden porch, and turn left on to the main road, Wide Street. Continue walking along the pavement beside the road. You pass a large corrugated iron factory building (Portland Eng. Co Ltd.). At the end of the rough path, turn left and walk back down the path, with the metal fence to your left and houses to your right. Cross the street, turn right and walk back to No.52.

Returning to where I started I think about how these three short tracks, taken as whole, are a meditation on viewing - and listening too - Portland as a sculptural object. The experience of the walk enables the listener to gain multiple perspectives of Portland's form, like viewing an art object in a gallery. The act of moving around it is intrinsically pleasurable because the listener is given the agency to connect associations and think through the object. The Loss Adjusters sound track takes a similar form to an audio guide in a museum, individualizing the encounter for each listener. This situates the listener at the center of the encounter, so that it is up to each individual to forge connections making the encounter 'live'.

This is what good sounding practice produces - beyond audio quality and technological sophistication - an artwork that makes the listener present. As Brandon Labella states, there is a capacity within sound, as a ubiquitous presence in everyday life, to both locate and dislocate experiences of place: 'sound is promiscuous. It exists as a network that teaches us how to belong, to find place as well as how not to belong, to drift. To be out of place and still to search for new connection, for proximity' (2010, xvii). The precise pleasures of being made to feel present in The Loss Adjusters derives from the forms of theatrical latency encountered; the reassurance and menace from the fictional conceit of the loss adjusters as spectral figures leading the listener through the various spaces of the island; the philosophical propositions of Palmer about the nature of material presence; the dynamic reverbs and processed effects of voices suggesting distance and solemnity; the exactitude and sensitivity of the sound design to the natural sounds of the island; the effect of distracted listening; and the revitalizing of objects and materials as part of the theatrical 'Walkman effect'.

To return to Voegelin's quote, which opened this article, good sounding work enables a co-habitation with sound. In The Loss Adjusters this co-habitation is the feeling of being present somewhere: remembering something, seeing something, experiencing something. Gumbrecht states, 'we have no reason to believe at least no systematic reason that what has entered a latent state will ever show itself or, conversely, not be forgotten one day' (2010, 23). The utilization of theatricality as a pleasurable effect - through sound - suggests a way to access states of latency. By making The Loss Adjusters, Palmer has made hidden things visible so they are not forgotten, maintaining a stake in the present and the future of Portland. I see the place slightly differently now and feel, if only for a day, I have actually been there.

\section{Notes}

${ }^{1}$ Walking instructions are included throughout the text. They are taken from a map given out with the audio. It is composed by Palmer and Artangel and unattributed.

\section{References}

Augoyard, Jean-François, and Henry Torgue. 2011. Sonic Experience: A Guide to Everyday Sounds. London: McGill-Queen’s University Press. 
Badiou, Alain. 2007. "A Theatre of Operations: A Discussion between Alain Badiou and Elie During.” In A Theatre without Theatre, edited by Manuel J. Borja-Villel, 22-27. Barcelona: Museu d'Art Contemporani de Barcelona.

Fisher, Mark. 2014. Ghosts of my life: Writings on Depression, Hauntology and Lost Futures. Winchester: Zero Books.

Fried, Michael. 1998. Art and Objecthood. Chicago: University of Chicago Press.

Goodman, David. 2010. "Distracted Listening: On Not Making Sound Choices in the 1930s." In Sound in the Age of Mechanical Reproduction edited by David Suisman and Susan Strasser. Philadelphia: University of Pennsylvania Press.

Gumbrecht, Hans Ulrich. 2010. After 1945: Latency as Origin of the Present. Stanford: Stanford University Press.

Hosokawa, Shuhei. 2012. “The Walkman Effect.” In The Sound Studies Reader, edited by Jonathan Sterne, 104-116. Abingdon: Routledge.

LaBelle, Brandon. 2010. Acoustic Territories: Sound Culture and Everyday Life. London: Bloomsbury

Lehmann, Hans-Thies. 2006. Postdramatic Theatre. Abingdon: Routledge.

J.Borja-Villel, Manuel. 2007. “A Theatre without Theatre: The Place of the Subject.” In A Theatre without Theatre, edited by Manuel J. Borja-Villel, 20-21. Barcelona: Museu d'Art Contemporani de Barcelona.

Palmer, Katrina. 2015. End Matter. London: Artangel and Book Works.

Voegelin, Salomé. 2014. Sonic Possible Worlds. London: Bloomsbury.

Voegelin, Salomé. 2010. Listening to Noise and Silence: Towards a Philosophy of Sound Art. London: Continuum.

Wilson, Helen F. 2016. "Sonic Geographies, Soundwalks and More-Than-Representational Methods.” In The Auditory Culture Reader, edited by Michael Bull and Les Back, 163172. London: Bloomsbury. 